\title{
The Antecedents and Challenges of Innovation in Sustainable Development Projects: Systematic Review
}

\author{
Afaf Hassan \\ Department of Environmental Health and Safety, Abu Dhabi University \\ PO Box 59911, Abu Dhabi, United Arab Emirates \\ Tel: 971-2501-5555Ｅ-mail: afaf.h-adjunct@adu.ac.ae
}

Received: January 12, 2021 Accepted: February 18, $2021 \quad$ Published: February 21, 2021

doi:10.5296/emsd.v10i1.18329 URL: https://doi.org/10.5296/emsd.v10i1.18329

\begin{abstract}
This study demonstrates the antecedents and challenges of innovation in sustainable development (SD) projects. In particular, a systematic literature review is conducted to highlight the challenges of innovation, that can suppress the efficient attainment of innovation benefits, in SD projects. The findings indicate that the positive benefits of innovation, in SD projects, are applying new strategies, developing new management practices, increasing interests and commitments of project team members, obtaining a better quality, attaining competitive advantages, introducing active influencers, establishing more engagement and collaborative work among team members, and satisfying project stakeholders. On the other side, innovation challenges that could act as barriers to achieve these benefits, in SD projects, are innovation resistance, stakeholders' requirements, pressure from clients to meet the SD project goals, diverse project environment, dynamic and unstable markets, project structure and characteristics, compliance with the common goals between innovation and sustainable development projects, and less management support and commitment for innovation. In brief, if project team members could overcome these challenges, innovation could be adopted and implemented effectively in sustainable development projects.
\end{abstract}

Keywords: Innovation benefits, Innovation challenges, Sustainable development projects

\section{Introduction}

\subsection{Introduce the Problem}

The growing concern about the high consumption of resources, environmental degradation, and social injustice requires a transition towards sustainable economies and societies (Adams et al., 2016). However, sustainable development stands for improvements that meet the 
existing generations' demands without compromising future generations' capacity to meet their own demands. The perception of sustainable development as per the "triple bottom line" demonstrates that generations are urged to adopt successful mechanisms and correspond effectively to economic, environmental, and social aspects in decision-making, to adopt suitable innovation that has the ability to enhance the outcome of SD project (Adams et al., 2016). Yet, attaining sustainable development often proposes a change or modification of projects, or even a particular stage of that project, considering its surrounding environment (Evans et al., 2017).

Accordingly, the need for innovation is emerging as a potential approach to integrating sustainable development into projects (Evans et al., 2017). In this study, innovation describes any new ideas that stand for a new design, method, process, or technology that is used in a particular SD project (Dulaimi et al., 2005; Ling et al., 2007; Murphy et al., 2015; Paladino, 2007; Samson \& Gloet, 2014). The implementation process of innovation requires substantial time to arrange accurate schedules that can be followed by managers and involved project team members (Chuang et al., 2011). Earlier work trends had treated sustainable development projects dichotomously, as such projects can end up being sustainable or not sustainable. This is not accurate, since the involved project members should consider the dynamic of the sustainable development projects and the unfolding processes that are accomplished over time (Adams et al., 2016). Here, it is important to mention that innovation is associated with high uncertainty, which comes in four main forms that are organizational, market, resource, and technical uncertainty (O'Connor \& Rice, 2013). Uncertainty is also linked to the behaviors of project team members concerning the three pillars of sustainability (economic, environment, and society) (Evans et al., 2017). Hence, each one of these types of uncertainty is considered in an innovation context and is distinguished through two elements that are expectancy and importance (O'Connor \& Rice, 2013). Bearing in mind that uncertainty is associated with innovation processes and outcomes, it is widely agreed that the implementation of innovation in SD projects creates a great challenge for involved individuals (Evans et al., 2017). This indicates that challenges are typical when working in an innovation context that involves high uncertainty (Chatenier et al., 2010). Consequently, being innovative in the domain of sustainable development requires robust capabilities, whether related to small, incremental, or radical innovation steps (Evans et al., 2017).

It is important to study the antecedents and challenges of innovation in sustainable development projects for several reasons. In justification, innovation contributes to economic growth, elevated living standards, and competitive advantages (Ozorhon, 2013). Innovation aims to shape future opportunities; improve current products, services, or procedures; and implement effective new internal and external ideas (Ende et al., 2015). Innovative has the ability to increase SD projects' effectiveness and convey long-term benefits (Dulaimi et al., 2005). In addition, innovation is essential to stimulate SD projects, renew activities, and ensure survival in today's' dynamic world. Innovation is also mobilized to track environmental and social goals (Dulaimi et al., 2005). Still, when applying innovation in SD projects, one fundamental sustainability question is: "What are the innovation tasks projects employ to be sustainable?" Therefore, it is important to plan for innovation, sensitively, to 
achieve the desired sustainable development goals (Adams et al., 2016).

However, the main aim of this research is to analyze the challenges of innovation that can suppress the attainment of innovation benefits in sustainable development projects. Thus, this systematic literature review attempts to study the benefits of innovation in SD projects; investigate the challenges of innovation in SD projects; and examine the existence of an association between innovation challenges and the attainment of innovation benefits in sustainable development projects.

\section{Method}

This exploratory research is based on the preceding literature related to the topic of the study, which is about innovation and sustainable development projects. The literature was reviewed systematically in four main stages. First, the concepts of innovation and sustainable development projects were explained. Second, the arguments supporting the existence of a relationship between innovation and SD projects were selected. Third, the most important benefits of innovation in SD projects were highlighted. Fourth, the critical innovation challenges that influence the adoption and implementation of innovation in sustainable development projects were emphasized. However, providing adequate knowledge and information throughout these four steps required the researcher to find reliable peer-reviewed journal articles. Initially, a random selection of fifty-five articles, that are relevant to the topic of this research, was performed. Each article was read by the author, and contents discussing innovation challenges, innovation benefits, and the existence of an association between innovation challenges and benefits in SD projects were identified. Then, it was found out that forty-four journal articles were directly related to this research. Thus, the valuable knowledge and information obtained from these articles had been used to satisfy the main purpose of this study, which is analyzing the challenges of innovation that can suppress the attainment of innovation benefits in SD projects.

\section{Literature Review}

\subsection{What is Innovation?}

Innovation has been defined several times (Dulaimi et al., 2005; Ling et al., 2007; Murphy et al., 2015; Paladino, 2007; Samson \& Gloet, 2014). Each definition has unique characteristics about innovation, but the most frequently revealed element in all definitions is "newness" (Dulaimi et al., 2005; Ling et al., 2007; Murphy et al., 2015; Paladino, 2007; Samson \& Gloet, 2014). In particular, innovation is described as an efficient application of novel ideas, strategies, processes, services in projects (Dulaimi et al., 2005). It is the formation, advancement, and achievement of ideas that are new to projects and has practical benefits, entailing the adoption and implementation of novel products or processes (Murphy et al., 2015; Dulaimi et al., 2005). Innovation is also known as a different idea that an individual adopts in a project to gain more benefits, considering any possible uncertainties or risks that might take place (Ling et al., 2007). Here, it is crucial to mention that such novel ideas can stand for a new design, material, technique, or technology that is used in a specific project (Ling et al., 2007). Innovation can be considered as an organization's capability to embrace 
new ideas, products, and processes successfully (Dulaimi et al., 2005; Paladino, 2007). It is a new way of accomplishing something, and a positive alteration to drive something or someone to be better than before (Dulaimi et al., 2005). Innovation points out that something is new but does not, necessary, has to be new to everyone (Samson \& Gloet, 2014). In other words, innovation can be new to particular consumers, industries, processes, or business prototypes that can result in positive advantages such as cost reductions (Samson \& Gloet, 2014). Considering all of these definitions, this study defines innovation as any novel idea, process, product, or service that is adopted, implemented, and delivered effectively in projects.

\subsection{What is A Sustainable Development Project?}

There are many arguments about the definition of sustainable development projects, specifically when considering the differences in sustainability goals among and within diverse societies (Ciegis et al., 2011; Fukuda-Parr \& Muchhala, 2020; Remington-Doucette $\&$ Musgrove, 2015). Numerous scholars have agreed that sustainable development can be defined as a blend of, economic growth, environmental protection, and social inclusion (Ciegis et al., 2011; Fukuda-Parr \& Muchhala, 2020; Remington-Doucette and Musgrove, 2015; Sachs, 2012; Wiek et al., 2011). In specific, sustainable development has been described as enhancing the living standards of individuals through ending poverty and inequity and enhancing the national and global economies to develop the environment (Ciegis et al., 2011; Fukuda-Parr \& Muchhala, 2020; Sachs, 2012). This indicates that sustainable development main targets are improving the economy, encouraging social equity, and protecting the environment. Still, it is imperative to point out that sustainable development projects are projects that motivate recent generations to satisfy their needs without compromising the aptitude of future generations to meet their needs (Remington-Doucette \& Musgrove, 2015). In other words, SD projects are effective, as they are concerned about improving the three key pillars of sustainability (economic, environment, and society) (Secundo et al., 2020; Ciegis et al., 2011). Furthermore, sustainable development projects are highly demanded for many reasons (Secundo et al., 2020; Sobol, 2008; Wiek et al., 2011). For example, SD projects respond effectively to any existing or potential problems such as climate change, desertification, poverty, or pandemics (Wiek et al., 2011). Secundo et al. (2020) has added that sustainable development projects can be considered as efficient solutions for multidimensional challenges such as pollution, climate change, migration, food security, ecosystem resilience, biodiversity, equality, peace, energy, economic growth, education, gender, healthcare, and sustainable production. However, the demand for sustainable development projects requires innovative products, methods, and processes that motivate a wide range of stakeholders to adopt and implement such projects (Sobol, 2008; Wiek et al., 2011). This explains that the implementation of innovative methods, strategies, procedures, and processes is very important to complete SD projects successfully (Veenendaal \& Bondarouk, 2015). Hence, overcoming any challenges associated to innovation in sustainable development projects is essential, to attain the required benefits of innovation and move forward towards successful sustainable development projects (Ciegis et al., 2011; Fukuda-Parr \& Muchhala, 2020; Sachs, 2012). 


\subsection{Innovation Processes in Sustainable Development Projects}

The innovation process is any change that alters the way a particular job is performed, the way an activity is designed, or the way an implementation is accomplished (Smeds, 2001). Hence, innovation process is a chain of stages that begin with recognizing opportunities to implement new products, tools, or technologies in sustainable development projects (Sheu \& Lee, 2011). Thomas et al. (2012) have argued that innovation has four main processes, which are realizing the new idea, standardizing the tasks, tailoring the implementation to meet the project needs, and pruning away any unnecessary practices. Here, it becomes clear that through following these simple innovation processes, sustainable development projects can be improved. On the other site, other scholars have argued that innovation process includes three main elements that are idea initiation, idea championing, and idea implementation (Veenendaal \& Bondarouk, 2015). First, idea initiation implies that individuals recognize barriers and opportunities in sustainable development projects and produce novel ideas as solutions. Second, idea championing allows the team members of SD projects to move a generated idea into practice. Third, idea implementation is that stage that applies new ideas in a sustainable development project (Veenendaal \& Bondarouk, 2015). In this study, understanding the typical stages of an innovation process helps in recognizing how innovation can lead to successful sustainable development projects.

\subsection{Innovation Management in Sustainable Development Projects}

Effective innovation management is essential for the attainment of a successful innovation process (Song, et al., 2015). This brings to attention that it is imperative to understand how innovation can be managed efficiently. Thomas et al. (2012) have emphasized five key innovation management stages that are the creation of an innovation context; management of innovation processes; initiation of innovation processes; generation of suitable innovation content; and implementation of innovation results (Bossink, 2002). At a later stage, it has been found out that innovation management (in SD projects) is also concerned about establishing a balance between "stimulation and support", and "control and direction setting" phases (Ende et al., 2015). The phase of "Stimulation and support" builds a culture of creativeness that motivates individuals to generate, select, and develop ideas. In turn, the quality and quantity of ideas are increased. Whereas the phase of "Control and direction setting" assures that the new ideas meet the project's aims through setting standards, directing processes, and eventually choosing the best ideas. This results in not only reducing the number of unnecessary ideas but also increasing the quality of a project's strategy. Although undertaking both steps simultaneously create tension, successful management of such tension leads to better innovation outcomes (Ende et al., 2015).

Moreover, innovation management can be considered as a social process, as involved individuals collaborate to innovate and influence others through their innovation (Ende et al., 2015). According to Dulaimi et al. (2005), there are different methods for innovation management for an individual and a team. Individual innovation management is concerned about the creativeness of individuals. The reason is that the innovativeness of someone is highly influenced by their personality and ability to risk novel ideas (Ende et al., 2015). 
Individuals can apply creative thinking strategies and share them effectively (Shieh, 2011). Team innovation management refers to the innovative abilities of project team members (Dulaimi et al., 2005; Ende et al., 2015). Teams' innovation management can be achieved through developing the creativeness of present project team members within that particular SD project (Shieh, 2011). In brief, innovation management can be achieved successfully in sustainable development projects through the following two critical points. First, initiating approaches, methods, and tools that provide more creative ideas. Second, managing the generated ideas efficiently (Ende et al., 2015).

Henceforth, strengthening innovation management is necessary to enhance success and market positioning (Shieh, 2011). This can be obtained through incorporating effective methods of management; alternating management structure to suit diverse settings; encouraging an individual to produce innovative management ideas; and establishing a positive culture (Shieh, 2011). In this study, understanding innovation management is essential to explain innovation challenges that could be confronted by project management and team in SD projects.

\subsection{Innovation Benefits in Sustainable Development Projects}

Although some sustainable development projects have previously failed to maintain or attain the benefits of innovation (Murphy et al., 2015), it is imperative to highlight the great benefits that innovation can bring to such projects. In justification, innovative projects concentrate on gaining individuals' loyalty through finding out what is important to them, and engaging them in meaningful issues (Hassan, 2020; Murphy et al., 2015; Samson \& Gloet, 2014; Shieh, 2011). This indicates that engaging employees effectively to deliver innovation, is one of the key benefits of innovation. Innovation also helps in determining various technology choices and how such technologies are leveraged to produce high quality innovations, resulting in desired sustainable development projects' outcome (Siguaw et al., 2006). This implies that selecting the right technology advances the overall outcome of sustainable development projects, specifically resulting in attaining high quality projects. In addition, another benefit is creating an effective innovation culture, as this helps the SD project team members move away from old ways of performing traditional projects (Shieh, 2011). This is done through developing a creative approach for innovation processes and becoming more committed to policies that are associated with innovation management (Shieh, 2011). Here, it is obvious that an innovative culture improves the manners of thinking, executing, and implementing innovation (Shieh, 2011). At the same time, innovation addresses client needs and problems through offering novel products, processes, and service (Sheu and Lee, 2011). Innovation also suggests unique customer benefits, incredible cost reductions, and willingness to initial new projects, any of which can result in better SD projects' outcome (Slater et al., 2014). Samson and Gloet (2014) have added that innovation produces new customer value, as it reduces costs, builds proficiencies, and offers better end user outcomes. Here, it is valuable to highlight that end users' satisfaction can be considered as one of the main advantages of innovation. Looking forward at more benefits of innovation leads to the argument of Ende et al. (2015), as they have pointed out that idea generation skills are imperative for projects' success in recent competitive environments. This demonstrates that innovation has the 
capability to improve the economy, offer better quality, and deal with present competitions (Ende et al., 2015). Yet, the commitment that innovation passes to SD projects' team members can be seen as a benefit. In support, Samson and Gloet (2014) have mentioned that innovation does not only improve projects' quality, but also displays a robust sense of commitment towards it.

However, when implementing sustainable development projects, it is vital to be aware that innovation benefits differ depending on projects' objectives, as innovation might bring huge financial benefit to a particular project, while it might only enhance the performance of another project (Ozorhon, 2013). Besides, innovation can be very beneficial, for projects in general and project team members in particular, when considering four main factors that are project work environment, team members' interests, assigned tasks, and individuals' skills (Ling, 2003). Other factors that can influence the extent of innovation benefits in sustainable development projects are innovation aims, skills, coordination methods, monitoring techniques, training, opportunities, challenges, efforts made, constraints, and commitments (Ling et al., 2007). Nevertheless, innovation can bring outstanding benefits to sustainable development projects as shown in Table 1 .

Table 1. The benefits of innovation in sustainable development projects

\begin{tabular}{|c|l|l|}
\hline No. & Innovation benefits in SD projects & \multicolumn{1}{c|}{ References } \\
\hline 1 & Development of new strategies & $\begin{array}{l}\text { Dulaimi et al., 2005; Ciegis et al., 2011; Ling et al., 2007; Sachs, } \\
\text { 2012; Seaden et al., 2003; Secundo et al., 2020; Siguaw et al., } \\
\text { 2006; Veenendaal \& Bondarouk, 2015 }\end{array}$ \\
\hline 2 & $\begin{array}{l}\text { Establishment of new management } \\
\text { practices }\end{array}$ & $\begin{array}{l}\text { Dulaimi et al., 2005; Fukuda-Parr \& Muchhala, 2020; Hassan, } \\
\text { 2020; O'Connor and Rice, 2013; Remington-Doucette \& } \\
\text { Musgrove, 2015; Wiek et al., 2011 }\end{array}$ \\
\hline 3 & $\begin{array}{l}\text { Increase in management and project } \\
\text { team interests and commitments }\end{array}$ & $\begin{array}{l}\text { Ciegis et al., 2011; Ling, 2003; Remington-Doucette \& } \\
\text { Musgrove, 2015; Wiek et al., 2011 }\end{array}$ \\
\hline 4 & Quality improvement & $\begin{array}{l}\text { Bossink, 2002; Ciegis et al., 2011; Ende et al., 2015; Ozorhon, } \\
\text { 2013; Sachs, 2012; Secundo et al., 2020 }\end{array}$ \\
\hline 5 & Competitive advantages & $\begin{array}{l}\text { Ende et al., 2015; Fukuda-Parr \& Muchhala, 2020; Jiao \& Zhao, } \\
\text { 2014; Remington-Doucette \& Musgrove, 2015; Seaden et al., } \\
\text { 2003; Wiek et al., 2011 }\end{array}$ \\
\hline 6 & Availability of active influencers & $\begin{array}{l}\text { Ciegis et al., 2011; Hassan, 2020; Howell et al., 2005; Ozorhon, } \\
\text { 2013; Remington-Doucette \& Musgrove, 2015; Wiek et al., 2011 }\end{array}$ \\
\hline 7 & $\begin{array}{l}\text { Engagement and collaborative work } \\
\text { among project team members }\end{array}$ & $\begin{array}{l}\text { Adams et al., 2016; Ende et al., 2015; Fukuda-Parr \& Muchhala, } \\
\text { 2020; Hassan, 2020; Ozorhon, 2013; Remington-Doucette \& } \\
\text { Musgrove, 2015; Wiek et al., 2011 }\end{array}$ \\
\hline 8 & Satisfaction of project stakeholders & $\begin{array}{l}\text { Adams et al., 2016; Ende et al., 2015; Murphy et al., 2015; } \\
\text { Ozorhon, 2013; Samson \& Gloet, 2014; Secundo et al., 2020 }\end{array}$ \\
\hline
\end{tabular}

\subsection{Innovation Challenges in Sustainable Development Projects}

The challenges of adopting and implementing innovation in sustainable development projects have received significant attention from managerial, tactical, and marketing viewpoints (Bohlmann, et al., 2013). In general, it is widely recognized that projects may undergo various barriers and resistance to innovations (Chatenier et al., 2010; Dulaimi et al., 2005; Gambatese \& Hallowell, 2011; Gray \& Davies, 2007). This can take place due to numerous 
reasons such as the separation of the design and implementation stages in an innovation development process (Murphy et al., 2015). In clarification, any novel technology adopted during design stage struggles to continue during the implementation stage to meet a complete outcome (Murphy et al., 2015). In turn, this demands an effective SD project design and implementation plan to reduce any potential for failure (Murphy et al., 2015). Another concern is the complexity of innovation, which is a result of a wide variety of innovation tasks that may range from introducing new products or processes to introducing creative management strategies (Gray \& Davies, 2007). Further, typical challenges such as innovation context, cognitive distances, high diversity, low social solidity, poor learning climate, low mutual commitment, high ambiguity, low resources availability, power differentiations, and absenteeism from traditional hierarchical borders influence innovation in SD projects (Chatenier et al., 2010). Moreover, additional costs of innovation, inexperienced employees, inaccessibility to desired material, and resistance to change are considered to be critical challenges to achieving innovation benefits in sustainable development projects. Such challenges could not only have the ability to discourage the SD project team members, but also make them reluctant to invest in new products, methods, processes, or services (Gambatese \& Hallowell, 2011).

In addition, innovation challenges (in SD projects) occur due to the lack of suitable conditions (Adams et al., 2016; Ernst et al., 2015; Samson \& Gloet, 2014). This signifies that the failure to initiate the right conditions for a successful adoption of innovation may leads to further problems in SD projects. For example, lack of efficient ways to obtain, share, use and transfer knowledge resources to match the SD project context; inadequate evaluation of project team members (including all stakeholders); or unsuitable project culture (Samson \& Gloet, 2014). Commonly, innovation concentrates on technology, but sometimes, it may lack the needed facilities to apply the required changes (Adams et al., 2016). Hence, lacking the required facilities to implement innovation in SD projects can prevent team members from adopting new approaches and techniques, to solve problems or allocate resources in creative ways (Ernst et al., 2015). Thus, in this study, the main innovation challenges that influence sustainable development projects are demonstrated in Table 2. 


\section{Macrothink \\ Environmental Management and Sustainable Development \\ ISSN 2164-7682 \\ 2021, Vol. 10, No. 1}

Table 2. Challenges of innovation in sustainable development projects

\begin{tabular}{|c|l|l|}
\hline No. & Innovation challenges in SD projects & \multicolumn{1}{c|}{ References } \\
\hline 1 & Innovation resistance & $\begin{array}{l}\text { Adams et al., 2016; Chatenier et al., 2010; Chuang et al., 2011; } \\
\text { Dibrov, 2015; Dulaimi et al., 2005; Fukuda-Parr \& Muchhala, } \\
2020 ; \text { Gambatese \& Hallowell, 2011; Gray \& Davies, 2007; } \\
\text { Secundo et al., 2020; Wiek et al., 2011 }\end{array}$ \\
\hline 2 & $\begin{array}{l}\text { Stakeholders' requirements are not } \\
\text { being conveyed effectively }\end{array}$ & $\begin{array}{l}\text { Adams et al., 2016; Dulaimi et al., 2005; Chuang et al., 2011; } \\
\text { Samson \& Gloet, 2014; Secundo et al., 2020; Song et al., 2015 }\end{array}$ \\
\hline 3 & $\begin{array}{l}\text { Pressure from clients to meet the goals } \\
\text { of a sustainable development project }\end{array}$ & $\begin{array}{l}\text { Adams et al., 2016; Evans et al., 2017; Ling et al., 2007; Sachs, } \\
\text { 2012; Samson \& Gloet, 2014; Wiek et al., 2011 }\end{array}$ \\
\hline 4 & The diverse project environment & $\begin{array}{l}\text { Adams et al., 2016; Bohlmann, et al., 2013; Fukuda-Parr \& } \\
\text { Muchhala, 2020; Gambatese \& Hallowell, 2011; Hartmann, } \\
\text { 2006; Shieh, 2011; Wiek et al., 2011 }\end{array}$ \\
\hline 5 & $\begin{array}{l}\text { The dynamic and unstable markets } \\
\text { Edams et al., 2016; Dulaimi et al., 2005; Ende et al., 2015; } \\
\text { Evans et al., 2017; Jayaram et al., 2014; Reichstein et al., 2005 }\end{array}$ \\
\hline 6 & $\begin{array}{l}\text { Project structure and characteristics } \\
\text { Adams et al., 2016; Dulaimi et al., 2005; Evans et al., 2017; } \\
\text { Fukuda-Parr \& Muchhala, 2020; Gambatese \& Hallowell, } \\
\text { 2011; Remington-Doucette \& Musgrove, 2015 }\end{array}$ \\
\hline 7 & $\begin{array}{l}\text { Compliance with the common goals } \\
\text { between innovation and sustainable } \\
\text { development projects }\end{array}$ & $\begin{array}{l}\text { Dulaimi et al., 2003; Fukuda-Parr \& Muchhala, 2020; Ling et } \\
\text { al., 2007; O'Connor \& Rice, 2013; Ozorhon, 2013; } \\
\text { Remington-Doucette \& Musgrove, 2015; Sachs, 2012; } \\
\text { Secundo et al., 2020; Wiek et al., 2011 }\end{array}$ \\
\hline 8 & $\begin{array}{l}\text { The project management support and } \\
\text { commitment to innovation }\end{array}$ & $\begin{array}{l}\text { Adams et al., 2016; Chuang et al., 2011; Ciegis et al., 2011; } \\
\text { Dulaimi et al., 2005; Hassan, 2020; Kelley \& Lee, 2010; } \\
\text { Remington-Doucette \& Musgrove, 2015; Wiek et al., 2011. }\end{array}$ \\
\hline
\end{tabular}

\section{Discussion}

In this study, the antecedents indicate that innovation adds several benefits to sustainable development projects (Adams et al., 2016; Bossink, 2002; Dulaimi et al., 2005; Hassan, 2020; Howell et al., 2005; Jiao \& Zhao, 2014; Ling, 2003; Murphy et al., 2015; Ozorhon, 2013; Seaden et al., 2003). In clarification, innovation initiates new strategies, requires new management practices, increases the interests and commitments, improves quality, creates competitive advantages, produces energetic influencers, enhances engagement and collaborative work, and rises stakeholder's satisfaction in sustainable development projects (Adams et al., 2016; Bossink, 2002; Dulaimi et al., 2005; Howell et al., 2005; Jiao \& Zhao, 2014; Ling, 2003; Murphy et al., 2015; Ozorhon, 2013; Seaden et al., 2003). Consequently, adopting and implementing innovation is necessary to enhance the overall outcome of SD projects.

In contrast, innovation is associated with many challenges that can act as barriers to achieve its benefits in SD projects (Adams et al., 2016; Bossink, 2002; Dulaimi et al., 2005; Howell et al., 2005; Jiao \& Zhao, 2014; Ling, 2003; Murphy et al., 2015; Ozorhon, 2013; Seaden et al., 2003). In justification, innovation resistance is one of the main challenges of innovation in SD projects (Adams et al., 2016; Chatenier et al., 2010; Chuang et al., 2011; Dibrov, 2015; Dulaimi, 2003; Dulaimi et al., 2005; Fukuda-Parr \& Muchhala, 2020; Gambatese \& Hallowell, 2011; Gray and Davies, 2007; Secundo et al., 2020; Wiek et al., 2011). It is a combination of internal and external elements (Dibrov, 2015). Internal elements can be 
economic, psychological, or social (Dibrov, 2015). The external elements can be cultural, industrial, legal, or political (Dibrov, 2015). These factors, if not set accurately, prevent individuals and organizations from adopting innovation in projects (Dibrov, 2015). Thus, innovation resistance is considered to be a principal challenge for individuals seeking to implement innovations in sustainable development projects (Chuang et al., 2011). Unfortunately, most often, this resistance can be turned into innovation rejection, even without providing practical reasons (Talke \& Heidenreich, 2014). In such cases, the implementation process of innovation ends even before it starts in SD projects (Talke \& Heidenreich, 2014). Further, if the Stakeholders' requirements are not being conveyed effectively in SD projects, this can be considered as a critical innovation challenge (Adams et al., 2016; Dulaimi et al., 2005; Chuang et al., 2011; Samson \& Gloet, 2014; Secundo et al., 2020; Song, et al., 2015). In explanation, some stakeholders cannot explain their needs precisely when introducing innovation in SD projects (Song, et al., 2015). In some other cases, the project team members might interpret the stakeholders' requirements inaccurately (Song, et al., 2015). Therefore, SD project team members can listen carefully to the stakeholders, when discussing their requirements are expectations, to avoid any misunderstanding that can occur. Henceforward, the concerned individuals in SD projects are encouraged to reorganize innovation practices through developing a novel approach that integrates anticipated and present stakeholder collaboration (Adams et al., 2016). Pressure from clients to meet the sustainable development project goals is another key innovation challenge in SD projects (Adams et al., 2016; Evans et al., 2017; Ling et al., 2007; Sachs, 2012; Samson \& Gloet, 2014; Wiek et al., 2011). The reason is that clients may add pressure on SD project team members in different ways such as requesting for adding new features to the products or services, introducing new technology, improving product or service quality, offering cost reductions, implementing different processes or strategies (Dulaimi et al., 2005; Chuang et al., 2011; Samson \& Gloet, 2014; Secundo et al., 2020). Hence, pressures from clients will always be there to develop adequate strategies, communicate the main goals and values, and improve the quality of sustainability projects (Adams et al., 2016). This requires project team members to acquire robust competencies and skills to overcome such a challenge (Hassan, 2020). The diverse project environment is an innovation challenge that can vary from one SD project to the other (Adams et al., 2016; Bohlmann, et al., 2013; Fukuda-Parr \& Muchhala, 2020; Gambatese \& Hallowell, 2011; Hartmann, 2006; Shieh, 2011; Wiek et al., 2011). In particular, projects that operate in diverse places, countries or regions have different cultures (Adams et al., 2015; Hartmann, 2006). Diversity influences the SD projects' capability to develop innovative products and services in the evolving markets (Adams et al., 2016; Bohlmann, et al., 2013). The dynamic and unstable markets are challenging as well (Adams et al., 2016; Dulaimi et al., 2005; Ende et al., 2015; Evans et al., 2017; Jayaram et al., 2014; Reichstein et al., 2005). Where the end user's demands are commonly changing, SD projects struggle to seize opportunities that can help not only in implementing innovation successfully, but also gaining better involvement in current markets (Jayaram et al., 2014). This is predominantly understood by SD project team members, who serve new markets with innovative products or services (Adams et al., 2016). When applying innovation in an unstable market, it is essential to predict possible real and substantial 
developments that determine positive economic, environmental, and social influences in existing dynamic markets (Evans et al., 2017). Indeed, it is challenging to get adapted to dynamic markets due to the typical innovation implementation processes that separate one project from another (Reichstein et al., 2005). In explanation, the nature of these dissimilar markets highly impacts the potential to complete innovation successfully in SD projects (Reichstein et al., 2005). Still, another innovation challenge in SD projects is the ambiguous Projects' characteristics and structure (Adams et al., 2016; Dulaimi et al., 2005; Evans et al., 2017; Fukuda-Parr \& Muchhala, 2020; Gambatese \& Hallowell, 2011; Remington-Doucette $\&$ Musgrove, 2015). The reason is that innovation can be adopted and implemented successfully in some SD projects compared to others depending on these projects' characteristics and structure (Gambatese \& Hallowell, 2011). When adopting innovation, the sustainable development project team members are responsible to enhance the level of sustainability outcomes such as resource depletion, waste to landfill, energy use, and emissions. To achieve this, the project team members need to develop a better understanding of the pillars of sustainability, and what behavioral, operational, and policy interventions are needed to facilitate such innovations in different project structures (Evans et al., 2017). Yet, the restructured practices that come from technological advances improve the outcomes of innovation in sustainable development projects (Adams et al., 2016). Compliance with the common goals between innovation and sustainable development projects is a significant innovation challenge (Dulaimi et al., 2003; Fukuda-Parr \& Muchhala, 2020; Ling et al., 2007; O'Connor \& Rice, 2013; Ozorhon, 2013; Remington-Doucette \& Musgrove, 2015; Sachs, 2012; Secundo et al., 2020; Wiek et al., 2011). In support, project team members should understand and have the aptitude to handle the shared goals of their SD project and innovation (Dulaimi et al., 2003; O'Connor \& Rice, 2013; Ozorhon, 2013). Such common goals frequently cover developing quality of work within one's own project; strengthening positive influences in projects; enhancing project performance; and securing reputation through delivering innovation in SD projects successfully (Dulaimi et al., 2003). Here, it is important to clarify that both common and individual goals (between innovation and sustainable develoment) are to be considered when applying innovation in SD projects (Evans et al., 2017). Adequate management support for innovation is a core innovation challenge in sustainable development projects. In justification, moving forward towards an accurate application of innovation requires finding out the most suitable time and methods to provide managerial support (Kelley \& Lee, 2010). Simultaneously, it is imperative to realize how much support is needed to implement innovation successfully in SD project (Kelley \& Lee, 2010). This implies that management commitment towards innovation is significant for the success of innovation in SD projects (Adams et al., 2016). Ultimately, lack of project management support and commitment for innovation is another innovation challenge in SD projects (Adams et al., 2016; Chuang et al., 2011; Ciegis et al., 2011; Dulaimi et al., 2005; Hassan, 2020; Kelley \& Lee, 2010; Remington-Doucette \& Musgrove, 2015; Wiek et al., 2011). Such support and commitment result in identifying sustainable development policies, communicating sustainable development goals and values effectively, enhancing communications between functional departments, and attaining long-term aims and strategies that are essential for sustainability context (Adams et al., 2016). Besides, establishing reward 
systems and incentives create collaborative project team members, who are committed to achieve innovation goals successfully in SD projects (Adams et al., 2016).

As a result, the studied antecedents and challenges of innovation in sustainable development projects facilitate the successful adoption and implementation of new ideas, methods, processes, and technologies in SD projects. Thus, once innovation challenges are clearly identified, it becomes easier to overcome those challenges leads to obtaining more innovation benefits in sustainable development projects.

\section{Conclusion}

Innovation adds numerous benefits to sustainable development projects (Adams et al., 2015; Bossink, 2002; Dulaimi et al., 2005; Howell et al., 2005; Jiao \& Zhao, 2014; Ling, 2003; Murphy et al., 2015; Ozorhon, 2013; Seaden et al., 2003), as it introduces new strategies and management practices; interests and commitments; quality improvement; competitive advantages; active influencers; engagement and collaboration; and stakeholders satisfaction in SD projects (Adams et al., 2015; Bossink, 2002; Dulaimi et al., 2005; Howell et al., 2005; Jiao \& Zhao, 2014; Ling, 2003; Murphy et al., 2015; Ozorhon, 2013; Seaden et al., 2003). On the other side, obtaining such innovation benefits in SD projects can be difficult. The reason is that there are many innovation challenges that can delay or stop the attainment of the required benefits of innovation in sustainable development projects. In this study, innovation challenges in SD projects are resisting innovation, approaching stakeholders' requirements ineffectively, having pressure from clients to meet the SD project goals, confronting a diverse project environment, struggling with the dynamic and unstable markets, dealing with ambiguous project structure and characteristics, being able to deal with the common goals between innovation and sustainable development projects, and lacking the needed project management support and commitment for innovation (Adams et al., 2016; Chatenier et al., 2010; Chuang et al., 2011; Dibrov, 2015; Dulaimi, 2003; Dulaimi et al., 2005; Fukuda-Parr \& Muchhala, 2020; Gambatese \& Hallowell, 2011; Gray \& Davies, 2007; Hassan, 2020; Secundo et al., 2020; Wiek et al., 2011). Each one of these innovation challenges can stop the management and team members from achieving the needed benefits of innovation. Thus, concerned individual in SD projects are required to study those challenges thoroughly. This allows them to move in the right direction that is overcoming, or preferably avoid, the expected innovation challenges in SD projects.

However, based on the findings of this review, project managers as well as project team members are recommended to understand the existing or anticipated challenges of innovation before commencing SD projects. The reason is that this will help them accept innovation, understand the stakeholders' requirements precisely, handle client's requirements easily, work smoothly in a diverse project environment, work flexibly in dynamic or unstable markets, demonstrate awareness about project characteristics and structure, focus on achieving the common goals between innovation and sustainable development, and gain more project management support and commitment for innovation in SD projects. In turn, this can allow the project team members to realize the required innovation benefits in sustainable development projects. In addition, the researcher proposes directions for future research. 


\section{Macrothink}

Environmental Management and Sustainable Development

ISSN 2164-7682

2021, Vol. 10, No. 1

Further research can empirically examine the benefits of innovation in SD projects, investigate the challenges of innovation in SD projects, and confirm the existence of a relationship between applying innovation successfully and attaining the required innovation benefits in sustainable development projects.

\section{Acknowledgments}

Many thanks to the previous researchers who have contributed their knowledge about innovation and sustainable development projects.

\section{References}

Adams, R., Jeanrenaud, S., Bessant, J., Denyer, D., \& Overy, P. (2016). Sustainability oriented Innovation: A Systematic Review. International Journal of Management Reviews, 18(2), 180-205. https://doi.org/10.1111/ijmr.12068

Bohlmann, J. D., Spanjol, J., Qualls, W. J., \& Rosa, J. A. (2013). The Interplay of Customer and Product Innovation Dynamics: An Exploratory Study. Journal of Product Innovation Management, 30(2), 228-244. https://doi.org/10.1111/j.1540-5885.2012.00962.x

Bossink, B. A. G. (2002). The strategic function of quality in the management of innovation. Total Quality Management, 13(2), 195-205. https://doi.org/10.1080/09544120120102432

Chatenier, E., Verstegen, J. A. A. M., Biemans, H. J. A., Mulder, M., \& Omta, O. S. W. F. (2010). Identification of competencies for professionals in open innovation teams. $R \& D$ Management, 40(3), 271-280. https://doi.org/10.1111/j.1467-9310.2010.00590.x

Chuang, E., Jason, K., \& Morgan, J. C. (2011). Implementing complex innovations. Health Care Management Review, 36(4), 369-379. https://doi.org/10.1097/HMR.0b013e3182100cc2

Ciegis, R., Kliucininkas, L., \& Ramanauskiene, J. (2011). Assessment of state and tendencies of sustainable development in Lithuania. Management of Environmental Quality: An International Journal, 22(6), 757-768. https://doi.org/10.1108/14777831111170858

Dibrov, A. (2015). Innovation Resistance: The Main Factors and Ways to Overcome Them. Procedia - Social and Behavioral Sciences, 166, 92-96.

https://doi.org/10.1016/j.sbspro.2014.12.489

Dulaimi, M. F., Ling, F. Y. Y., \& Bajracharya, A. (2003). Organizational motivation and inter-organizational interaction in construction innovation in Singapore. Construction Management and Economics, 21(3), 307-318. https://doi.org/10.1080/0144619032000056144

Dulaimi, M. F., Nepal, M. P., \& Park, M. (2005). A hierarchical structural model of assessing innovation and project performance. Construction Management and Economics, 23(6), 565-577. https://doi.org/10.1080/01446190500126684

Ende, J., Frederiksen, L., \& Prencipe, A. (2015). The Front End of Innovation: Organizing Search for Ideas. Journal of Product Innovation Management, 32(4), 482-487.

|https://doi.org/10.1111/jpim.12213 


\section{Macrothink}

Environmental Management and Sustainable Development

ISSN 2164-7682

2021, Vol. 10, No. 1

Ernst, H., Kahle, H. N., Dubiel, A., Prabhu, J., \& Subramaniam, M. (2015). The Antecedents and Consequences of Affordable Value Innovations for Emerging Markets. Journal of Product Innovation Management, 32(1), 65-79. https://doi.org/10.1111/jpim.12171

Evans, S., Vladimirova, D., Holgado, M., Van Fossen, K., Yang, M., Silva, E. A., \& Barlow, C. Y. (2017). Business Model Innovation for Sustainability: Towards a Unified Perspective for Creation of Sustainable Business Models. Business Strategy and The Environment, 26(5), 597-608. https://doi.org/10.1002/bse.1939

Fukuda-Parr, S., \& Muchhala, B. (2020). The Southern origins of sustainable development goals: Ideas, actors, aspirations. World Development, 126, 104706.

https://doi.org/10.1016/j.worlddev.2019.104706

Gambatese, J. A., \& Hallowell, M. (2011). Enabling and measuring innovation in the construction industry. Construction Management and Economics, 29(6), 553-567.

https://doi.org/10.1080/01446193.2011.570357

Gray, C., \& Davies, R. J. (2007). Perspectives on experiences of innovation: the development of an assessment methodology appropriate to construction project organizations. Construction Management and Economics, 25(12), 1251-1268.

https://doi.org/10.1080/01446190701573692

Hartmann, A. (2006). The context of innovation management in construction firms. Construction Management and Economics, 24(6), 567-578.

https://doi.org/10.1080/01446190600790629

Hassan, A. (2020). Managerial Competencies Required to Achieve Sustainable Development Projects: A Proposed Model for Managers. Environmental Management and Sustainable Development, 9(3), 68-86. https://doi.org/10.5296/emsd.v9i3.17603

Howell, J. M., Shea, C. M., \& Higgins, C. A. (2005). Champions of product innovations: defining, developing, and validating a measure of champion behavior. Journal of Business Venturing, 20(5), 641-661. https://doi.org/10.1016/j.jbusvent.2004.06.001

Jayaram, J., Oke, A., \& Prajogo, D. (2014). The antecedents and consequences of product and process innovation strategy implementation in Australian manufacturing firms. International Journal of Production Research, 52(15), 4424-4439.

https://doi.org/10.1080/00207543.2013.849363

Jiao, H., \& Zhao, G. (2014). When Will Employees Embrace Managers' Technological Innovations? The Mediating Effects of Employees' Perceptions of Fairness on Their Willingness to Accept Change and its Legitimacy. Journal of Product Innovation Management, 31(4), 780-798. https://doi.org/10.1111/jpim.12123

Kelley, D., \& Lee, H. (2010). Managing Innovation Champions: The Impact of Project Characteristics on the Direct Manager Role. Journal of Product Innovation Management, 27(7), 1007-1019. https://doi.org/10.1111/j.1540-5885.2010.00767.x

Ling, F. Y. Y. (2003). Managing the implementation of construction innovations. 
Construction Management and Economics, 21(6), 635-649.

https://doi.org/10.1080/0144619032000123725

Ling, F. Y. Y., Hartmann, A., Kumaraswamy, M., \& Dulaimi, M. (2007). Influences on Innovation Benefits during Implementation: Client's Perspective. Journal of Construction Engineering and Management, 133(4), 306-315.

https://doi.org/10.1061/(ASCE)0733-9364(2007)133:4(306)

Murphy, M. E., Perera, S., \& Heaney, G. (2015). Innovation management model: a tool for sustained implementation of product innovation into construction projects. Construction Management and Economics, 33(3), 209-232.

https://doi.org/10.1080/01446193.2015.1031684

O'Connor, G. C., \& Rice, M. P. (2013). A Comprehensive Model of Uncertainty Associated with Radical Innovation. Journal of Product Innovation Management, 30, 2-18.

https://doi.org/10.1111/jpim.12060

Ozorhon, B. (2013). Analysis of Construction Innovation Process at Project Level. Journal of Management in Engineering, 29(4), 455-463.

https://doi.org/10.1061/(ASCE)ME.1943-5479.0000157

Paladino, A. (2007). Investigating the Drivers of Innovation and New Product Success: A Comparison of Strategic Orientations. Journal of Product Innovation Management, 24(6), 534-553. https://doi.org/10.1111/j.1540-5885.2007.00270.x

Reichstein, T., Salter, A. J., \& Gann, D. M. (2005). Last among equals: a comparison of innovation in construction, services and manufacturing in the UK. Construction Management and Economics, 23(6), 631-644. https://doi.org/10.1080/01446190500126940

Remington-Doucette, S., \& Musgrove, S. (2015). Variation in sustainability competency development according to age, gender, and disciplinary affiliation: Implications for teaching practice and overall program structure. International Journal of Sustainability in Higher Education, 16(4), 537-575. https://doi.org/10.1108/IJSHE-01-2013-0005

Sachs, J. D. (2012). From Millennium Development Goals to Sustainable Development Goals. The Lancet, 379(9832), 2206-2211. https://doi.org/10.1016/S0140-6736(12)60685-0

Samson, D., \& Gloet, M. (2014). Innovation capability in Australian manufacturing organisations: an exploratory study. International Journal of Production Research, 52(21), 6448-6466. https://doi.org/10.1080/00207543.2013.869368

Seaden, G., Guolla, M., Doutriaux, J. \& Nash, J. (2003). Strategic decisions and innovation in construction firms. Construction Management and Economics, 21(6), 603-612. https://doi.org/10.1080/0144619032000134138

Secundo, G., Ndou, V., Vecchio, P., \& De Pascale, G. (2020). Sustainable development, intellectual capital and technology policies: A structured literature review and future research agenda. Technological Forecasting and Social Change, 153, 119917.

https://doi.org/10.1016/j.techfore.2020.119917 


\section{Macrothink}

Environmental Management and Sustainable Development

ISSN 2164-7682

2021, Vol. 10, No. 1

Sheu, D. D., \& Lee, H. (2011). A proposed process for systematic innovation. International Journal of Production Research, 49(3), 847-868.

https://doi.org/10.1080/00207540903280549

Shieh, C. (2011). Management innovation, corporation core competence and corporate culture: the impact of relatedness. Applied Economics Letters, 18(12), 1121-1124.

https://doi.org/10.1080/13504851.2010.526567

Siguaw, J. A., Simpson, P. M., \& Enz, C. A. (2006). Conceptualizing Innovation Orientation: A Framework for Study and Integration of Innovation Research. Journal of Product Innovation Management, 23(6), 556-574. https://doi.org/10.1111/j.1540-5885.2006.00224.x

Slater, S. F., Mohr, J. J., \& Sengupta, S. (2014). Radical Product Innovation Capability: Literature Review, Synthesis, and Illustrative Research Propositions. Journal of Product Innovation Management, 31(3), 552-566. https://doi.org/10.1111/jpim.12113

Smeds, R. (2001). Implementation of business process innovations: an agenda for research and action. International Journal of Technology Management, 22(1/2/3), 1-12.

https://doi.org/10.1504/IJTM.2001.002951

Sobol, A. (2008). Governance barriers to local sustainable development in Poland. Management of Environmental Quality: An International Journal, 19(2), 194-203. https://doi.org/10.1108/14777830810856573

Song, W., Ming, X., Han, Y., Xu, Z., \& Wu, Z. (2015). An integrative framework for innovation management of product-service system. International Journal of Production Research, 53(8), 2252-2268. https://doi.org/10.1080/00207543.2014.932929

Talke, K., \& Heidenreich, S. (2014). How to Overcome Pro-Change Bias: Incorporating Passive and Active Innovation Resistance in Innovation Decision Models. Journal of Product Innovation Management, 31(5), 894-907. https://doi.org/10.1111/jpim.12130

Thomas, J. L., Cicmil, S., \& George, S. (2012). Learning From Project Management Implementation by Applying a Management Innovation Lens. Project Management Journal, 43(6), 70-87. https://doi.org/10.1002/pmj.21308

Veenendaal, A., \& Bondarouk, T. (2015). Perceptions of HRM and their effect on dimensions of innovative work behaviour: Evidence from a manufacturing firm. Management Revue, 26(2), 138-160. https://doi.org/10.5771/0935-9915-2015-2-138

Wiek, A., Withycombe, L., \& Redman, C. L. (2011). Key competencies in sustainability: a reference framework for academic program development. Sustainability Science, 6(2), 203-218. https://doi.org/10.1007/s11625-011-0132-6

\section{Copyright Disclaimer}

Copyright for this article is retained by the author(s), with first publication rights granted to the journal.

This is an open-access article distributed under the terms and conditions of the Creative Commons Attribution license (http://creativecommons.org/licenses/by/4.0/). 